\title{
Aging and Nutrition
}

National Cancer Institute

\section{Source}

National Cancer Institute. Aging and Nutrition. NCI Thesaurus. Code C15659.

The study of how nutritional needs change with aging. 